\title{
Memoria y fiesta popular en Ayacucho. Escenarios de la comunicación en sociedades posconflicto
}

\author{
Yolanda Rodríguez González \\ Pontificia Universidad Católica del Perú, lima, Rerú \\ rodriguez.y@pucp.edu.pe
}

\begin{abstract}
RESUMEN
En mayo, la pequeña ciudad de Luricocha enclavada en la región andina centro sur del Perú, atrae a cantidad de visitantes motivados por la Fiesta de las Cruces. Ella moviliza a decenas de comunidades que llegan de diferentes barrios y pagos del distrito portando sus cruces adornadas con flores y tejidos coloridos para ser saludadas por la feligresía y turistas. Las cruces son acompañadas por los Chunchos, agrupaciones músico coreográficas que tocan un instrumento aerófono ancestral: la antara. Lo que aparece ante los ojos del visitante como un ritual ligado al pasado, está íntimamente imbricado con el presente y sus símbolos de modernidad: las tecnologías de la comunicación y la información. Las tecnologías son utilizadas para activar los lazos de identidad y pertenencia de la comunidad y su diáspora esparcida como consecuencia de la guerra interna en los años 80 .
\end{abstract}

Palabras clave: Comunicación intercultural, Ayacucho, sociedad posconflicto, fiesta popular, memoria colectiva

\section{Memory and popular festivity in Ayacucho. Communication scenarios in post-conflict societies}

\begin{abstract}
In May, the small town of Luricocha, located in the south-central Andean region of Peru, attracts numerous visitors interested in Fiesta de las Cruces (Festival of the Crosses). This festival causes the movement of dozens of communities from different neighborhoods and places of the district carrying their crosses adorned with flowers and colorful fabrics to be greeted by the parishioners and tourists. The crosses are accompanied by the Chunchos, musical and choreographic groups that play an ancestral aerophone instrument: the antara. What appears before the visitor's eyes as a ritual linked to the past is intimately intertwined with the present and its symbols of modernity: communication and information technologies. The technologies are used to activate the bonds of identity and belonging of the community and the diaspora scattered as a result of the internal war in the 80s.
\end{abstract}

KeYwORDs: Intercultural communication, Ayacucho, post-conflict society, popular festival, collective memory 


\section{Introducción}

Luricocha, pequeńa ciudad enclavada en los andes centro-sur del Perú, es escenario de una de las manifestaciones culturales más vistosas y complejas que ocurre cada ańo a inicios del mes de mayo, la Fiesta de las Cruces. El 3 de mayo, decenas de cruces de diverso tamaño y vistosidad provenientes de pagos, caseríos y comunidades aledańas del distrito de Luricocha en Huanta, portadas por sus fieles y acompañadas por conjuntos musicales, se congregan en la plaza principal y hacen su entrada en el templo católico para ser veneradas y "escuchar misa". Los días previos las cruces han descendido de las montańas o wamanis que rodean Luricocha, recorrido sus barrios recibiendo el saludo de los vecinos que han desarrollado una serie de rituales de preparación. Al final de la misa el día central, las cruces cargadas en hombros de sus fieles y siempre acompañadas por las agrupaciones musicales, dan una vuelta alrededor de la plaza principal y se despiden en carrera celebrada por la multitud. Las cruces, dependiendo del tamaño de la feligresía y la capacidad económica de la hermandad a cargo de cada una, lucen vistosos y ricos atuendos; otras más sencillas y pequeñas, no dejan de lucir sus galas de telas, flores y ramas aromáticas.

La Cruz se celebra en muchas localidades del país y está asociada con el ciclo agrícola; el mes de mayo coincide con el fin de las lluvias, es el gran mes de la cosecha, Hatun iaimoray Quilla, tiempo de abundancia y regocijo (Palomio Flores, 1968). Para muchos estudiosos la ceremonia de la cruz forma parte de un ancestral culto a las montańas; siendo el Razuwillca la más imponente de esta zona que se yergue a casi 5 mil metros de altura sobre el nivel del mar, dominando el paisaje de las provincias de Huanta y La Mar en Ayacucho. Aunque no se sabe a ciencia cierta de cuando data esta celebración, Millones \& Tomoeda (2010) señalan que, tal cual la conocemos hoy, debió iniciarse a mediados del siglo XVII.

La Fiesta de las Cruces convoca y moviliza a fieles de los caseríos y comunidades del distrito, así como a migrantes residentes en Huamanga, Lima o Miami que retornan con motivo de la Fiesta o se hacen presentes a través de alguna ofrenda. La Fiesta atrae a muchos visitantes de la región y fuera de ella, así como algunos extranjeros provenientes de los países vecinos, interesados por la cultura andina, principalmente por el toque ancestral de las antaras en el festival Atiq Chunchu. En efecto, una de las mayores atracciones de la Fiesta de la Cruces son los Chunchos, conjuntos músico-coreográficos que tocan antaras o flautas de pan, de diferentes tamaños según el número y diámetro de los tubos amarrados en una sola hilera (Arce Sotelo, 2009).

Originalmente confeccionadas de caña o carrizo, las antaras llegan a medir dos metros y sólo son ejecutadas en mayo, cuando los Chunchos acompañan a las cruces desarrollando una performance. Los ejecutantes, tradicionalmente varones, representan al habitante de la Amazonía vestido con la tradicional cushma, adornado con penachos de plumas, collares de semillas, animales disecados, pieles y flechas. Aunque la mayoría de 
los integrantes de las agrupaciones de Chunchos que participan en la Fiesta de las Cruces no son originarios de la selva, ellos se identifican y reconocen como tales durante la performance. De hecho, los Chunchos no representan, sino que son los habitantes que llegan de la vertiente oriental de esta parte de los Andes a la ciudad de Luricocha en el valle andino para acompañar a las cruces. Como dicen los locales y visitantes, "no hay Fiesta de las Cruces sin los Chunchos".

El gran número de visitantes que llega el día central de la Fiesta de las Cruces, lo hace por distintas motivaciones: culturales, religiosas, espirituales, comerciales; de estudio e investigación; de recreación y esparcimiento, degustación de comidas típicas, reencuentro familiar, figuran entre las principales razones para asistir a la Fiesta de las Cruces. Debido a que la ciudad de Luricocha tiene una muy reducida oferta de hospedaje para visitantes $y$, de otro lado, dista apenas a una hora de la ciudad de Huamanga capital de Ayacucho, los visitantes no pernoctan en Luricocha. No cabe duda sin embargo que La Fiesta de las Cruces de Luricocha es un fenómeno turístico que tiene impactos sociales, económicos y ambientales para la comunidad. No en vano, la Fiesta de las Cruces de Luricocha está en el portal oficial de turismo del Ministerio de Comercio Exterior y Turismo. La Dirección Regional de Comercio Exterior y Turismo, DIRCETUR de Ayacucho, difunde la Fiesta a través de afiches; el gobierno municipal de Luricocha difunde las actividades programadas cada año a través de la radio y su página en Facebook. Para este último, la Fiesta de las Cruces es una ocasión para promocionar la riqueza y variedad de la producción frutícola del valle cuyo producto emblemático es la palta de alta calidad e increíble variedad, cuya producción está mayormente destinada a la exportación.

Este desplazamiento temporal de poblaciones y personas hacia Luricocha con motivo de la Fiesta de las Cruces, así como el conjunto de actividades de producción y consumo aparejados a él, definen un fenómeno turístico que tiene impactos sociales, ambientales y económicos en y para la comunidad local. Se trata claramente de las interacciones de lo global en el espacio local. Un espacio local que tiene connotaciones y un significado particular en la reciente historia nacional abierta en los años 80 con el estallido del conflicto armado interno en Chuschi, Ayacucho, y los procesos posteriores a la finalización del conflicto; principalmente los procesos de retorno de las poblaciones desplazadas y de migrantes producto de la dinámica de la violencia política. Estos procesos implican la reconfiguración de espacios locales y de formas de habitar el territorio; de nuevas relaciones e interacciones que, ocurriendo en lo local, están en referencia con lo global al mismo tiempo. Se trata de dinámicas y procesos locales en las llamadas sociedades posconflicto aún poco estudiadas.

Observamos la Fiesta de las Cruces como un momento en el que se "activan las memorias" sobre el pasado reciente (Jelin 2012); las narrativas sobre la época de la violencia política afloran tímidamente en la coyuntura de la celebración de las cruces de mayo; cuando las personas comentan casi sin voluntad de ahondar en el asunto, que la 
cruz del Señor de Pachapunya erguida en la montańa que custodia la villa de Luricocha, fue dinamitada a inicios de los años 80 por locales simpatizantes de Sendero Luminoso. El relato de la destrucción de la cruz de Pachapunya está vivo en la memoria colectiva; hay sin embargo un silencio virtuoso en torno a la identidad de los perpetradores que expresaría un secreto compartido que antepone a los conflictos del pasado "las posibilidades restaurativas e integrativas de la convivencia en comunidad.” (del Pino, 2017, p.46). Enemigos de antaño, en el presente continúan siendo vecinos y como tales, vinculados por lazos de interdependencia; con ocasión de la Fiesta de las Cruces estos lazos se ponen de manifiesto a través del complejo sistema de mayordomías de base comunitaria.

Intentamos entender el fenómeno del turismo en Luricocha alrededor de esta manifestación de la cultura popular, sin perder de vista estas coordenadas básicas que la definen aunque no la limitan. El estudio cobra relevancia por tratarse de un evento que acontece en la región del Perú que fue el epicentro del fenómeno de la violencia política. La literatura internacional indica que el turismo puede desempeńar un papel de «conector» social y tiene el potencial de contribuir a la restauración del tejido social en sociedades posconflicto. Pero ¿qué condiciones son necesarias para que esto ocurra? Nuestro interés se dirige al conjunto de prácticas alrededor de aquello que convierte a la comunidad de Luricoha en un centro de atracción de múltiples y diversos actores que acuden en mayo: la Fiesta de las Cruces. En la Fiesta se producen procesos de comunicación que, con su opacidad y ambigüedad como bien señala Martín-Barbero (2012), muestran la complejidad real de la vida y la comunicación. En esa perspectiva, asumimos el desafío del autor al proponer el desplazamiento del concepto de comunicación al concepto de cultura; para enfatizar la importancia de, "[...] pensar sobre los procesos de socialización a través de los cuales una sociedad se reproduce, esto es sus sistemas de conocimiento, sus códigos de percepción, sus códigos de valoración y de producción simbólica de la realidad.” (p.80).

El texto presenta reflexiones fruto de una investigación interdisciplinaria que la autora realiza sobre la Fiesta de las Cruces de Luricocha con el objetivo de comprender las dinámicas de esta práctica social vista como coyuntura o momento de activación de memorias. El equipo de investigación realizó visitas de campo en Luricocha durante la Fiesta de las Cruces entre los años 2017 y 2019, en las cuales hicieron observaciones de las diferentes actividades que se desarrollan en la Fiesta, aplicaron encuestas a visitantes así como entrevistas y talleres con pobladores del distrito.

\section{Memoria y fiesta popular en Luricocha, Huanta}

Luricocha, con algo más de cinco mil habitantes, es uno de los ocho distritos que conforman la provincia de Huanta en el noreste de Ayacucho, una de las regiones 
más pobres del país. Situada a pocos minutos de la ciudad de Huanta, a menos de 60 minutos de la ciudad de Huamanga capital de Ayacucho, y a nueve horas de la ciudad de Lima por la carretera Vía Los Libertadores, vía transversal de penetración que comunica la carretera Panamericana Sur con la ciudad de Ayacucho. Huanta está comprendida en la región cocalera conocida como el Valle de los rios Apurímac y Ene conocido como el VRAE, el mayor centro de cultivo de coca del país y proveedor de coca al narcotráfico. La población de Luricocha se distribuye en unos quince pagos, tres comunidades campesinas y un centro poblado. Es un distrito en el que la migración permanente y temporal es alta, y cuya producción está fuertemente destinada a la comercialización.

Ayacucho fue una de las regiones más duramente afectada por el conflicto armado interno, principalmente las zonas de altura pobladas por comunidades campesinas; se calcula que 40\% de las muertes y desaparieciones de todo el periodo 1980-2000 ocurrieron en Ayacucho. Más de 600 mil peruanos de la zona centro sur y zona central del país tuvieron que huir de sus lugares de origen; muchos fueron ayacuchanos que se trasladaron de sus comunidades en el campo a ciudades como Huanta, siendo Lima el destino de un gran número de desplazados. Según la Comisión de la Verdad y Reconciliación del Perú (en adelante CVR), las víctimas mortales de la violencia política en Ayacucho fueron cerca de 45 mil personas, la gran mayoría campesinos e indígenas quechua hablantes (CVR, 2003). En Huanta, el desplazamiento de poblaciones reconfiguró la forma de ocupación del territorio por el despoblamiento del campo y el surgimiento de nuevos poblamientos urbanos, así como el crecimiento de las ciudades ya existentes. Emerge ahí el fenómeno de los de desplazados, poblamientos fruto de la migración forzosa hacia zonas del valle y hacia fuera de la región, principalmente a la ciudad de Lima.

La presencia del PCP-SL en Luricocha sin embargo es anterior al estallido de la primera acción amada. Heilman (2010a) indica que en las décadas 60-70 la hacienda Iribamba en Luricocha de propiedad de la familia de una de las principales dirigentes de la organización, sirvió como una de las primeras escuelas de entrenamiento militar.

Lejos de la visión de una población local atrapada "entre dos fuegos", ésta jugó un papel activo en el escenario del conflicto armado interno. Así por ejemplo, las comunidades en las alturas de Huanta, principales destinatarias de la prédica del PCP-SL, pasaron de un inicial apoyo al grupo, a un rechazo activo a sus pretensiones de sumisión. Sin duda el caso más conocido por la cobertura que recibió de parte de los medios de comunicación, fue lo ocurrido en las alturas de Huanta a inicios de enero de 1983 conocido como la matanza de los periodistas en Uchuraccay, Este hecho, según varios autores, sólo se explica en el contexto de las rivalidades entre comunidades y al interior de ellas previas al conflicto armado interno y exacerbadas por la dinámica del conflicto; 
un elemento clave en esta espiral de violencia habría sido la estrategia militar de agrupar a comunidades vecinas en aldeas multi comunales y armar a la población civil. Véase por ejemplo el CVR (2003) y Degregori et al. (1996).

Algunos autores (Theidon 2004, del Pino 2017, Coronel 1996) llaman la atención sobre la manera en que las diferencias en el grado de integración y comunicación, así como de los regímenes de tenencia de la tierra al interior de la región y en las localidades, influyeron en las diversas respuestas de las poblaciones durante el conflicto armado interno. La formación de los Comités de Defensa Civil (CDC) o rondas contrasubversivas a mediados de los 80 serían una expresión de estas dinámicas de diferenciación interna; los CDC supusieron un incremento en los niveles de violencia en la zona pues su acción no estuvo destinada única ni exclusivamente a luchar contra el grupo armado.

En el caso específico de Luricocha, Heilman (2010b) anota que la relación de la población con SL fue tan compleja como lo fue en otras comunidades; la autora señala que la mayoría de la población de Luricocha no simpatizaba con SL y que más bien esta ofreció activa resistencia a través de los CDC. Al igual que del Pino (2017) la autora plantea que el PCP-SL no fue un actor externo y ajeno a las comunidades, sino que estaba dentro de ellas dividiéndolas entre simpatizantes y opositores. Así, el PCP-SL captó simpatizantes y reclutó miembros entre algunos los jóvenes estudiantes luricochanos y huantinos con experiencia urbana y universitaria, a diferencia de sus padres. Se dieron entonces distintas respuestas de la población en el contexto del conflicto armado interno y que han dejado huella en las relaciones al interior de las comunidades, entre las comunidades vecinas y entre estas y el Estado.

El inicio del fin del conflicto armado con la captura del líder senderista en 1992 marca el inicio del retorno de las comunidades desplazadas a sus lugares de origen; son los retornantes que salieron presionados por la violencia y retornaron al cabo de un tiempo a los lugares de expulsión (Gamarra 2000). No regresan al pasado pues todo había sido alterado; principalmente las relaciones sociales, los sistemas de autoridad, jerarquía y poder que organizaban la vida social en las comunidades. Los que no se marcharon, las comunidades resistentes que no migraron compulsivamente y recibieron migrantes de otras comunidades (Gamarra 2000), reclaman para sí el reconocimiento de quienes enfrentaron al PCP-SL. En los procesos vividos tanto por los resistentes como por los retornantes, las iglesias evangélicas jugaron un papel muy importante que se expresa en la conversión de comunidades al evangelismo durante y después de la violencia política (Degregori, 1996). Este fenómeno está ligado a los procesos de concentración urbana fruto del desplazamiento de las comunidades de altura a las capitales de distrito y la experiencia urbana de los desplazados y migrantes. Así, Coronel (1996) anota que en el periodo 1981 y 1993 la población urbana en la provincia de Huanta pasó de 18\% a 39\%. Según los datos censales de 2007 
la población urbana de Huanta bordea el 50\%. Para Gamarra (2000) el crecimiento del evangelismo sería una forma de respuesta — adaptación y resistencia — al entorno cambiante en un periodo de rápido cambio y fuertes presiones externas. Las iglesias evangélicas jugaron un papel muy importante de resistencia, principalmente las iglesias evangélicas rurales pobres prácticamente la única organización social que quedó en un campo devastado por la guerra; las iglesias proveyeron un discurso religioso de resistencia a sus fieles y en algunos lugares se dio una estrecha relación entre los pastores locales y las rondas de autodefensa (CVR, 2003). Degregori (1996) observó ya a mediados de la década del 90 lo que llamó la "configuración de un nuevo centro simbólico" en numerosas localidades.

En Huanta, el proceso de retorno de los desplazados a sus comunidades de origen fue promovido por asociaciones de comunidades desplazadas en donde los evangélicos tuvieron una fuerte presencia. Los desplazados fueron socorridos material y espiritualmente por los "hermanos" en las ciudades en donde se asentaron; ayacuchanos como ellos, los hermanos migraron a Lima y a otras ciudades en mediados del siglo 20 en donde se convirtieron al evangelismo y mantuvieron vínculos con sus comunidades de origen; los hermanos ayudaron a los desplazados a encontrar trabajo, los incorporaron a sus iglesias, les proveyeron de una red social en los lugares de refugio (Gamarra 2000). Pero muchas cosas cambiaron en las décadas siguientes hasta nuestros días. Ya la urgencia por el temor y luego la reconstrucción cedieron el paso a nuevas formas de habitar el territorio y demandas de una sociedad andina más urbana en el contexto de la globalización.

¿Cómo se expresa el pasado reciente en la celebración actual de la Fiesta de las Cruces de Luricocha? Aun no lo sabemos cabalmente, pero cabe suponer que estas trasformaciones se expresan de alguna $\mathrm{u}$ otra forma en la celebración de mayo. En algunos lugares de Ayacucho como Chuschi, la Cruz ya no se celebra (Huber, 2002). En Luricocha pervive la celebración aunque concurren al día central, 3 de mayo mucho menos cruces que antaño, según testimonios recogidos en la localidad. No obstante, hay una voluntad de las autoridades y de la comunidad en mantener viva esta celebración. Relatos aislados recogidos en la localidad hablan de nuevas amenazas contra las cruces que provendrían de ciertos evangélicos; el relato de la quema de algunas cruces trae a la memoria el atentado contra una de las cruces principales de Luricocha hace 30 años en manos del PCP-SL. En efecto, a inicios de los años 80, la cruz del Señor de Pachapunya fue destruida con dinamita por algunos locales simpatizantes del PCPSL. A partir de entonces esta cruz se mantiene en una capilla a mitad de camino de la montańa y una nueva fue puesta en su lugar en la cúspide; ambas son sin embargo el Señor de Pachapunya. 


\section{Una descripción de la Fiesta de las Cruces de Luricocha}

[...] la cruz exige respeto y tributos de fe (flores, incienso, limpieza de su capilla y altar) y un público que le rece, le narre sus cuitas y le prometa sacrificios y regalos. (Millones et al., 2010, p. 52)

La Fiesta de las Cruces de Luricocha tiene lugar entre el 30 de abril y el 3 de mayo; aunque los preparativos empiezan antes pues la organización de la Fiesta muestra una gran complejidad por las diferentes funciones que ejercen las hermandades con sus mayordomos, antimayordomos y cargadores de las cerca de cincuenta cruces que participan en la celebración.

Las cruces proceden de los pagos, comunidades, caseríos y barrios del distrito de Luricocha; inclusive algunas llegan de distritos aledaños como Santillana. El 30 de abril de madrugada inicia la celebración con el descenso de cada cruz de la montańa, altura o casa donde ella se encuentra; llegan al valle trasportadas en hombros o en moto taxi por los fieles de la hermandad acompañados de agrupaciones musicales de Chunchos. El 3 de mayo las cruces llegan al atrio de la iglesia y hacen su entrada al templo en estricto orden de jerarquía; primero entran las dos cruces principales, la del Señor de Pachapunya y la Cruz del señor de Huatuscalle, la "cruz corredora"; luego entraran las demás cruces provenientes de diferentes comunidades: Pampay, Huayllay, Llancca, Pumaqasa, Yuraraccay, Izcutaco, Intay, muchas otras. El conjunto de Chunchos de cada cruz, diez a quince individuos mayormente hombres, realiza una performance en el atrio, tocando simultáneamente sus antaras mientras realizan desplazamientos en círculo. Mientras se desarrolla la misa, las agrupaciones continúan tocando en el atrio y la plaza hasta que salen las cruces y las acompañan en su recorrido alrededor de la plaza hasta que se retiran en carrera en hombros de los fieles devotos. El 4 de mayo las cruces retornan a su lugar de origen hasta el año siguiente, en el que la persona que recibe la mayordomía asumirá el cargo acompańada de su pareja o una persona de su confianza.

Durante los días previos al día central en que se celebra la misa, las cruces son preparadas por las hermandades correspondientes. Se puede apreciar la presencia de todos estos elementos en la víspera de la Cruz del Señor de Pachapunya; sin pretender una descripción exhaustiva del ritual, los siguientes elementos muestran su riqueza y complejidad. Al igual que ocurre con la Cruz de Huatuscalle a la Cruz de Pachapunya los fieles atribuyen grandes poderes para curar enfermedades y obrar milagros en quien pide con fe y cumple con lo que le ofrece. Los fieles además, deben cuidar del buen estado de las cruces a lo largo del año, tanto de aquella que está en la capilla como de la que permanece en lo alto de la montańa.

Cuentan los pobladores que la Cruz de Pachapunya fue dinamitada por el PCPSL en 1981; el relato del hecho está vivo en la memoria colectiva. Anotan Millones et 
al. (2010) que, “[...] un doble milagro siguió a la ofensa: las astillas desprendidas del tronco de la cruz fueron recogidas son sangre, lo que motivó un repudio generalizado, y quien llevara a cabo el atentado murió de manera miserable.” (p. 75). El relato del atentado ha sido recogido también en ocasión del trabajo de campo realizado en los tres últimos años en Luricocha y en Lima. Es probable que los pobladores de Luricocha conozcan la identidad de los autores el atentado quienes aparentemente no fueron externas a la localidad; las personas nombran el hecho, pero al intentar indagar un poco más en la circunstancia, invariablemente responden que no se encontraban en la localidad cuando éste ocurrió. Este "silencio" virtuoso" tomando prestado en término de del Pino (2017), expresaría un olvido voluntario, un secreto compartido que antepone a los conflictos del pasado "las posibilidades restaurativas e integrativas de la convivencia en comunidad." (p.46).

La víspera del día central, en la capilla construida en la ladera de la montaña a mitad de camino en la comunidad de Chamana, se da inicio a los preparativos con la entrega del cargo al mayordomo o mayordoma que el Señor "eligió" ese año; en la capilla se velará las dos cruces del Señor de Pachapunya desde el amanecer del día 1 hasta la mańana del 3 de mayo cuando descenderá a la iglesia de Luricocha. Durante todo ese tiempo, orquestas amenizan la ceremonia. En el segundo día se realiza la ceremonia del Amarre del Señor de Pachapunya en la cual las cruces son vestidas y preparadas para su descenso a la iglesia. Los maderos son vestidos con flores y hoyas de arrayán, romero y clavel; cubiertos por capas de tules de suaves colores, enseguida por chalinas de paño bordado y cintas de colores. Todo el ritual es ejecutado por varones quienes, trepados en un andamio ya que la cruz mide más de cinco metros, van colocando las telas una sobre otra, que las mujeres han traído envueltas en sus llicllas; hablan en quechua. Mientras visten la Cruz, se realiza un rezo u oración del ritual católico en castellano dirigido por algunas mujeres Cuando la cruz finalmente está vestida, le colocan el rostro que es la imagen del rostro de Cristo enmarcado; el rostro es alcanzado desde abajo del andamio y recibido de forma muy ceremoniosa por los hombres que le hablan y besan la imagen antes de pasarla al siguiente y finalmente colocarlo en el cruce de los dos maderos; por último, colocan una estola bordada con el recorte que permite exponer el rostro. Para finalizar, sujetan las telas a los maderos con llicllas. Así vestidas, las cruces del Señor de Pachapunya son veladas durante toda la noche; la comida, la bebida y la música provista por la mayordomía garantizan que el Señor de Pachapunya tendrá compañía hasta la mañana siguiente en que emprende el camino a la iglesia para la misa. La música está a cargo de una banda de instrumentos de viento metal traída de Huancayo o Huancavelica, donde tienen fama estas orquestas. Lo que no falta en la velada de las cruces es la música de las antaras de los Chunchos.

En medio del bullicio y de la música de la orquesta hacen su entrada los Chunchos del señor de Pachapunya; una decena de hombres jóvenes y mayores vestidos con 
cushmas, adornados con objetos propios de la Amazonía y portando cada uno una antara de diferente tamaño. Esperan su turno sentados en las bancas, lo que permite un breve dialogo con el joven Chuncho que está sentado a mi lado. Me cuenta que la mayoría de sus colegas son de Luricocha y que otros han venido de Lima para tocar; me dice que ellos tocan por fe, son voluntarios y no cobran por tocar a la Cruz; me cuenta que aprendió a tocar la antara en la academia de Yuraraccay, empezó tocando un instrumento de ocho tubos y ahora toca uno de doce; al preguntarle por qué las plumas de su penacho son de plástico me explica que así es mejor, "en vez de matar animales"; en efecto las plumas que coronan su cabeza están hechas de botellas plásticas y están pintadas con vivos colores; los otros adornos de su vestimenta son conchas naturales y algunos objetos pequeños de plástico.

Cuando ha terminado el ritual de vestir las cruces, lo que ha tomado aproximadamente dos horas, se hace el silencio y los Chunchos encuentran su momento; tocan sus antaras y luego se arrodillan frente a la Cruz y el mayor del grupo de músicos dirige una oración en quechua; terminado esto, los Chunchos se retiran de la capilla sin dar la espalda al Señor de Pachapunya. La vigilia continúa hasta la mañana siguiente en que llevan en hombros la Cruz a la iglesia en la plaza principal. Será la primera Cruz en entrar al templo, seguida del Señor de Huatuscalle; luego van entrando las demás cruces menores que se han dado cita en la Fiesta de las Cruces de Luricocha. Una de ellas lleva en el lugar del rostro de Cristo, el símbolo del tao que representa la dinámica del yin y del yang del universo en la tradición milenaria china. Las agrupaciones musicales que han quedado afuera del templo siguen tocando y algunos asistentes bailan en la plaza. Entre las agrupaciones de Chunchos, una llama la atención: junto con las antaras de sus compañeros de agrupación llegados de Lima, un joven toca un didjeridu, instrumento ancestral de los pueblos originarios de Australia.

En el templo una multitud espera la llegada de las cruces y su disposición en el frontis de la iglesia; el cura toca un bombo y canta en quechua con algunos Chunchos y el coro de la parroquia. Transcurre la misa y las cruces se retiran del templo. Afuera se realiza una procesión de cruces presidida por los notables de Luricocha, el alcalde, el cura y otras autoridades y personalidades. Luego de ejecutar un paseo alrededor del parque central, las cruces se retiran en carrera para el disfrute de los asistentes. Entre el público asistente abundan los celulares que de manera instantánea disparan fotos y videos por todo el mundo; paralelamente todo lo que sucede en el atrio de la iglesia y en la plaza principal de la ciudad es registrado por un dron de la municipalidad provincial de Huanta que transmite en directo el acontecimiento y las imágenes serán luego replicadas en las redes sociales y en los programas de televisión regional. Las redes sociales y la radio por internet son el principal medio de difusión de las actividades que se desarrollan durante la Fiesta de las Cruces; su alcance atrae la participación de agrupaciones musicales venidas de otras latitudes. 
El retorno de las cruces al lugar donde permanecerán hasta el siguiente año, es tan ceremonioso como la preparación durante la víspera del día 3 de mayo. Al Señor de Pachapunya lo acompañan en su retorno al calvario en la cúspide de la montańa, la multitud de los fieles portando guiones, comida y bebida, los cargadores y la orquesta de instrumentos de viento metal. En el primer descanso a menos de la mitad de camino, se detiene el grupo liderado por las señoras que llegan cantando un jarawi en quechua; descansan unos minutos, beben chicha y reponen fuerzas antes de continuar el camino; se aprecia una hermosa vista del valle desde esa altura y es posible entablar un breve dialogo con la joven sentada a mi lado que dejó Luricocha hace unos años para estudiar y trabajar en Lima; ella regresa cada año en mayo trayendo el guión de paño bordado con hilo dorado que manda fabricar en la capital. En la cima, ya en el calvario, habrá baile y comida para despedir al Señor de Pachapunya.

Todo el desarrollo de la Fiesta está a cargo de los grupos de fieles devotos o hermandades de cada cruz, no existe una organización centralizada. El papel del párroco se limita a las actividades que acontecen el día central, 3 de mayo, al interior de la iglesia a donde las cruces llegan para escuchar misa y ser saludadas por la concurrencia que repleta el templo ese día.

Los días previos a la celebración de la misa, la parte central de la pequeña ciudad ha sido ocupada por una feria de productores frutícolas del distrito que exhiben la increíble variedad de la fruta emblemática de Luricocha: paltas y chirimoyas; comerciantes y artesanos de otras regiones que han llegado con ocasión de la Fiesta; vendedoras de comida ofrecen sus platos típicos de la zona, carnes, dulces y bebidas; algunos músicos ofrecen talleres para conocer el toque de las antaras.

Hay mucha concurrencia y presencia de visitantes en el parque central y sus alrededores: muchas personas provienen de la vecina Huanta, de Huamanga y de Lima. Algunos son huantinos que residen hace años en Lima y regresan para la Fiesta de las Cruces; es una oportunidad de re encuentro familiar y amical. Vemos grupos de escolares con sus profesores y madres, de las escuelas primarias del distrito que han acudido porque sienten que es parte de su cultura; es un día martes y las profesoras expresan que la Fiesta se presta para hacer "diversificación curricular". También encontramos grupos de estudiantes de institutos de educación superior de Huanta que, fichas en mano, están recolectando datos de las ocurrencias que tienen lugar en la Fiesta; un grupo mayor de estudiantes de la Escuela Nacional de Folklore José María Arguedas ha llegado de Lima para conocer en situ la tradición y el origen de las danzas y la música que interpretan; un profesor de una universidad española ha venido de Lima a donde acudió para participar de un evento académico y donde le dieron referencias de una "fiesta de cruces" muy pintoresca no lejos de Ayacucho. Una familia chilena que viene recorriendo esta región del Perú en su propia movilidad, recaló en Luricocha porque había oído que algún evento interesante tendría lugar ahí en esos días. Otros jóvenes universitarios de 
Lima han venido también de Lima invitados por algunas agrupaciones de Chuchos para tocar antaras con ellos el día 3 de mayo; seguramente participarán también en el Hatun Tinkuy "Atiq Chunchu", un encuentro de conjuntos musicales ancestrales que se propone "evitar la desaparición de los Chunchos y las antaras de Luricocha", así mismo "fortalecer la identidad y promover el turismo cultural del distrito de Luricocha"; al Atiq Chunchu acuden músicos de Argentina, Chile, Bolivia y de otros países. La Fiesta de las Cruces es un encuentro multicultural.

La Fiesta de las Cruces de Luricocha comporta un complejo ciclo de celebraciones sostenido a su vez por un complejo sistema organizativo. El ciclo de celebraciones incluye los días previos y los días posteriores al 3 de mayo: la preparación de las cruces, las visitas de "adoración" que los Chunchos hacen a las cruces; el retorno de las cruces a su lugar de procedencia tiene también una serie de rituales y una organización social que se renueva cada ańo. Todo ello implica una compleja organización y el tejido de una red social extensa que hace posible la realización de la Fiesta cada año.

Inmediatamente culminada la Fiesta de las Cruces con la misa, según la programación oficial del gobierno local, se da inicio el Festival Nacional de la Palta, actividad de corte turístico comercial creado por la municipalidad distrital hace 20 años. La intención de las autoridades tras la creación del Festival de la Palta fue "levantar" la Fiesta de las Cruces que habría decaído en los años 80 producto de la inseguridad que se vivió entonces debido al conflicto armado interno y la migración forzada de cientos de pobladores. Ayacucho era entonces, como lo es aún, una de las regiones más pobres del país: se encuentra en los últimos lugares del ranking de Desarrollo Humano; la pobreza alcanza al $47 \%$ de la población; el analfabetismo femenino es $21 \%$; $26 \%$ de desnutrición crónica infantil; poco más del $30 \%$ de la población tiene secundaria completa, y 5 es el promedio de años de educación de la población de 25 ańos y más.

En ese contexto, la población de Luricocha y sus autoridades, ven en el desarrollo turístico una posibilidad de dinamizar la economía y salir de la pobreza. Luricocha tiene un patrimonio natural y cultural de representa una potencialidad; sin embargo tiene actualmente un bajo desarrollo de servicios e infraestructura para acoger adecuadamente a potenciales visitantes y turistas.

La Municipalidad distrital de Luricocha promociona la Fiesta de las Cruces y el Festival Nacional de la Palta mediante spots que se propalan por las emisoras de radio y televisión de alcance regional, principalmente Radio y TELE 2000 Huanta, señal de amplia cobertura y que se sintoniza también a través de Facebook. La difusión se hace

también mediante afiches producidos por la municipalidad, así como la Dirección Regional de Turismo de Ayacucho. En la visión de las autoridades el turismo puede jugar un rol importante dinamizando la economía y el desarrollo local.

La población de Luricocha ve con optimismo las oportunidades que la Fiesta de las Cruces ofrece para el desarrollo de la comunidad por la atracción de visitantes y 
turistas: se dinamizan el comercio y el intercambio de productos; la población participa activamente, vive un ambiente de unidad, celebración y alegría y se fortalece la dimensión espiritual en la comunidad; se revalora la cultura local y el patrimonio cultural; se generan oportunidades temporales de trabajo.

Sin embargo, la promoción del turismo alrededor de la Fiesta de las Cruces y del Festival Nacional de la Palta comporta también riesgos y amenazas para el bienestar de la comunidad. Diferentes grupos de vecinos - estudiantes y profesores; agricultores, músicos y comerciantes, así como autoridades-, fueron consultados sobre los impactos negativos de las actividades comerciales y artísticas promocionadas por el gobierno local. En primer lugar, señalan la falta de control de la venta de bebidas alcohólicas -el negocio más lucrativo en este tipo de eventos-, que trae como consecuencia inseguridad, agresiones físicas, asaltos e inclusive ataques sexuales contra mujeres de la localidad. En segundo lugar, mencionan la ausencia de un manejo eficiente de la producción de basura -sobre todo los deshechos de envases de material plástico y de tecnopor utilizado en la venta de alimentos y bebidas-, lo que produce daños a la salud y al ambiente. Otro impacto negativo mencionado es el incremento de los precios producto de la demanda generada por la llegada de visitantes y turistas, lo que perjudica a los pobladores del distrito. De manera similar, la llegada de los visitantes y turistas conlleva congestión de tránsito y desorden vehicular.

Frente a esta problemática, los mismos pobladores presentan algunas propuestas para mejorar los efectos sociales, ambientales y económicos negativos que se producen por efecto de la falta de una gestión adecuada de estas actividades. Es interesante destacar propuestas para mejorar la organización incorporando a diversos actores, el control de venta de bebidas alcohólicas, la gestión de desechos sólidos e implementación de servicios higiénicos; como también campañas de educación ambiental. Para los pobladores es importante recoger mediante encuestas el nivel de satisfacción de visitantes y turistas acerca de su experiencia en las festividades.

Una dimensión importante manifestada por los pobladores es la preservación de la tradición de la celebración de la Fiesta de las Cruces y la presencia de los Chunchos en ella. En efecto, está presente el riesgo de la pérdida paulatina de los sentidos de celebración por el paso del tiempo y la ausencia de políticas de cuidado de esta manifestación cultural. En ese sentido la producción de información dirigida tanto a la comunidad como al turista, acerca de la Fiesta de las Cruces y su significado para la comunidad luricochana, emerge como una clara y urgente necesidad.

Lo popular se revela no como un rezago del pasado ni folclórico; sino como prácticas sociales que producen sentidos y que expresan demandas de reconocimiento de identidad y como parte dinámica integrante de la configuración de la sociedad luricochana en el siglo 21. La cultura popular es contemporánea, dinámica e inmersa en tensiones que son las que le dan contemporaneidad; vive en el mundo interconectado y 
se sirve de sus medios para presentarse, mostrarse y buscar su espacio en él. La tensión es entre las demandas de autogestión y las tendencias homogenizadoras y mercantiles (García Canclini, 1987, p. 6)

\section{Algunas reflexiones finales}

Pensar la comunicación, la ciudad y el espacio público en países como el Perú, nos lleva a mirar el universo de pequeńas ciudades andinas que pueblan nuestro paisaje humano. Luricocha en Huanta, Ayacucho, es una muestra de este universo.

La festividad y celebración de las Cruces de Luricocha es un momento en el que los lazos de pertenencia que unen a la comunidad se renuevan; se actualizan en esa extensa y compleja red social de la organización de la Fiesta. Las asperezas y conflictos presentes en cualquier comunidad, de manera particular en aquellas que atravesaron divisiones profundas debido al conflicto armado interno, encuentran una oportunidad para limarse.

La Fiesta de las Cruces de Luricocha es un fenómeno complejo de celebración y de reencuentro; de renovación de los vínculos y razones de pertenencia de una comunidad. $\mathrm{Al}$ mismo tiempo genera expectativas de mejora material y progreso económico por el turismo que atrae. A pesar de que la comunidad desea recibir más visitantes, aún no ha logrado organizar servicios adecuados que permitan una experiencia de calidad.

Si bien la Fiesta cuenta con potencial para atraer un tipo de visitante con motivaciones culturales y responsable acorde a un turismo sostenible, se necesita que la comunidad desarrolle capacidades organizativas, de lo contrario corre el riesgo de generar efectos perjudiciales tanto para los visitantes como para la propia comunidad y su entorno.

Existen en el país decenas o cientos de localidades como Luricocha, pequeñas ciudades capitales de distrito, que dan forma al paisaje andino. Particularmente aquellas pequeñas ciudades que sufrieron el impacto de los procesos de la violencia política de las últimas décadas del siglo pasado; y que en los "tiempos de paz" son el escenario de nuevas configuraciones sociales que se asientan y tejen en la urdimbre de su memoria colectiva. La Fiesta de las Cruces de Luricocha hay que entenderla en ese tejido de historia, tradición y memoria, junto con visiones de futuro en las que el turismo atraído por estas tradiciones parece jugar un papel dinamizador.

Presentados estos elementos sobre la Fiesta de las Cruces de Luricocha, que no agotan por cierto la descripción de la riqueza de esta manifestación de la cultura popular, menos su análisis e interpretación, proponemos, parafraseando a Jesús Martín Barbero (2012), algunos puntos a modo de mapa nocturno, "[...] un mapa en el que más que ver se intuye, se siente por donde van las cosas, aunque quizás todavía no tenemos las palabras exactas para nombrarlas." (p.77). Lo que se manifiesta con claridad es el papel de la 
comunicación en los procesos de cambio; la tradición se revela no como algo pasadista, un arcaísmo o un rezago del pasado; sino como prácticas sociales que producen sentidos y que expresan demandas de reconocimiento de identidad y como parte dinámica integrante de la configuración de la sociedad luricochana, ayacuchana y por extensión peruana en el siglo 21. En estas dinámicas de una sociedad que atravesó transformaciones profundas, los actores locales como las agrupaciones de chunchos, la organización social que son las mayordomías de las cruces, como también el gobierno local, tomando prestados los términos de Martín-Barbero (2012), se reorganizan y rediseñan.

Mal haríamos en reducir y simplificar la comprensión de esta fiesta popular en el antagonismo arcaico/moderno, tradicional/moderno; es absolutamente contemporáneo, dinámico e inmerso en tensiones que justamente son las que le permiten y le dan contemporaneidad, presencia y significado hoy. La fiesta popular y sus actores viven en el mundo interconectado por los medios de comunicación; y se sirven de estos para presentarse, mostrarse y buscar su espacio en el mundo globalizado. Lo popular se revela no como un rezago del pasado ni folkórico; sino como prácticas sociales que producen sentidos y que expresan demandas de reconocimiento de identidad y como parte dinámica integrante de la configuración de la sociedad luricochana en el siglo 21 . La cultura popular es contemporánea, dinámica e inmersa en tensiones que son las que le dan contemporaneidad; vive en el mundo interconectado y se sirve de sus medios para presentarse, mostrarse y buscar su espacio en él. La tensión es entre las demandas de autogestión y las tendencias homogenizadoras y mercantiles (García Canclini, 1987, p. 6)

\section{Referencias}

Arce Sotelo, M. (2009). Continuidad y variedad en la música de los Chunchos de Luricocha. Perspectivas Latinoamericana, 6, 69-82.

Comisión de la Verdad y Reconciliación del Perú, CVR (2003). Informe Final. Capítulo 1. Lima.

Coronel, J. (1996). Violencia política y respuestas campesinas en Huanta. En Degregori et al. Las rondas campesinas y la derrota de Sendero Luminoso; pág. 29-116. Lima: IEP/Universidad Nacional de San Cristóbal de Huamanga.

Degregori, C.I., Coronel, J., del Pino, P. \& Starn, O. (1996). Las rondas campesinas y la derrota de Sendero Luminoso. Lima: IEP/Universidad Nacional de San Cristóbal de Huamanga.

Degregori, C.I. (1996). Ayacucho, después de la violencia. En Degregori et al. Las rondas campesinas y la derrota de Sendero Luminoso; pág. 14-28. Lima: IEP/Universidad Nacional de San Cristóbal de Huamanga.

Huber, L. (2002). Consumo, cultura e identidad en el mundo globalizado. Estudio de casos en los Andes. Lima: Instituto de Estudios Peruanos. 
Del Pino, P. (2017) En nombre del gobierno. El Perú y Uchuraccay: un siglo de política campesina. Lima: La Siniestra Ensayos, Universidad Nacional de Juliaca.

Gamarra. J. (2000). Conflict, Post-Conflict and Religion: Andean Responses to New Religious Movements. Journal of Southern African Studies, 26 (2), 271-287.

García Canclini, N. (1987) Ni folklórico ni masivo: ¿qué es lo popular? Diálogos de la comunicación (17), 4-11.

Guerrero González, P.E. \& Ramos Mendoza, J.R. (2014). Introducción al Turismo. México: Grupo Editorial Patria.

Heilman, J.P. (2010a). Family Ties: The Political Genealogy of Shining Path's Comrade Norah. Bulletin of Latin American Research, 29 (2), 155-169.

Heilman, J.P. (2010b). Before the Shining Path. Politics in rural Ayacucho, 1985-1980. Stanford, CA: Stanford University Press.

Jelin, E. (2012). Los Trabajos de la memoria. Lima: Instituto de Estudios Peruanos.

Martín-Barbero, J. (2012). De la Comunicación a la Cultura: perder el «objeto» para ganar el proceso. Signo y Pensamiento, XXX (60), 76-84.

Millones, L. \& Tomoeda, H. (2010). La Cruz del Perú. Lima: Fondo Editorial Pedagógico San Marcos.

Palomino Flores, S. (1968). La cruz de los Andes. Amaru. Revista de Artes y Ciencias, 8, 63-66.

PNUD. Informe sobre desarrollo humano Perú 2013: Cambio Climático y territorio: Desafios y respuestas para un futuro sostenible. Lima: PNUD.

Sancho, A. (coord.) (1998). Introducción al Turismo. Madrid: Organización Mundial del Turismo (OMT). Recuperado de https:/www.entornoturistico.com/ introduccion-al-turismo-la-omt-pdf/

Theidon, K. (2004). Entre prójimos. El conflicto armado interno y la politica de la reconciliación en el Perú. Lima: Instituto de Estudios Peruanos. 